\title{
Recent changes in the global and regional carbon cycle: analysis of first-order diagnostics
}

\author{
P. J. Rayner ${ }^{1}$, A. Stavert ${ }^{2}$, M. Scholze ${ }^{3}$, A. Ahlström ${ }^{3}$, C. E. Allison ${ }^{2}$, and R. M. Law $^{2}$ \\ ${ }^{1}$ School of Earth Sciences, University of Melbourne, Melbourne, Australia \\ ${ }^{2}$ CSIRO Oceans and Atmosphere Flagship, Melbourne, Australia \\ ${ }^{3}$ Department of Physical Geography and Ecosystem Science, Lund University, Sweden \\ Correspondence to: P. J. Rayner (prayner@unimelb.edu.au)
}

Received: 29 May 2014 - Published in Biogeosciences Discuss.: 25 June 2014

Revised: 17 November 2014 - Accepted: 8 January 2015 - Published: 11 February 2015

\begin{abstract}
We analyse global and regional changes in $\mathrm{CO}_{2}$ fluxes using two simple models, an airborne fraction of anthropogenic emissions and a linear relationship with $\mathrm{CO}_{2}$ concentrations. We show that both models are able to fit the non-anthropogenic (hereafter natural) flux over the length of the atmospheric concentration record. Analysis of the linear model (including its uncertainties) suggests no significant decrease in the response of the natural carbon cycle. Recent data points rather to an increase. We apply the same linear diagnostic to fluxes from atmospheric inversions. Flux responses show clear regional and seasonal patterns driven by terrestrial uptake in the northern summer. Ocean fluxes show little or no linear response. Terrestrial models show clear responses, agreeing globally with the inversion responses, however the spatial structure is quite different, with dominant responses in the tropics rather than the northern extratropics.
\end{abstract}

\section{Introduction}

The interplay of various timescales in anthropogenically forced climate change is both problematic and fascinating. It is problematic since temperature responses integrate radiative forcing and radiative forcing by greenhouse gases integrates sources. Thus changes in source processes can, if sustained, drive surprisingly large changes in the trajectory of temperature.

For the most important greenhouse gas, $\mathrm{CO}_{2}$, this double integration gives a respectable utility to an inherently fascinating question: are there changes in the underlying processes of the carbon cycle? The utility comes from the natural carbon cycle's role in mitigating the anthropogenic perturbation by absorbing about half the anthropogenic input of carbon to the atmosphere (Le Quéré et al., 2013). Optimal policy response relies on projections of this uptake so changes in the natural carbon cycle have direct policy implications.

We have had conceptual models for these changes for many years. For the ocean these are predominantly changes in chemical buffering (Revelle and Suess, 1957) and changes in physical circulation (Sarmiento et al., 1998). For terrestrial uptake there are many countervailing factors at work such as extension of the high latitude growing season (Zhou et al., 2001; Piao et al., 2008) and the varied responses of terrestrial ecosystems to changes in temperature and rainfall. Cox et al. (2000) combined many of these responses into a reasonably complete model of the earth system and projected a strong reduction in carbon uptake with the land becoming a net source around 2050. Friedlingstein et al. (2006) showed that this was one of many possible responses. Such studies naturally prompted observational tests of the important processes such as the reaction of the Amazon forest to drying (Saleska et al., 2003). Several studies have suggested sink saturation or reduction in various regions such as Schuster and Watson (2007) for the North Atlantic, Le Quéré et al. (2007) for the Southern Ocean and Nabuurs et al. (2013) for European forests.

Meanwhile the 5-decade record of atmospheric $\mathrm{CO}_{2}$ raises the possibility of detecting changes in the results of these processes directly. This was first taken up by Canadell et al. (2007) who suggested that sinks were saturating, at least relative to emissions. This was made more explicit by Raupach et al. (2008) who attempted to isolate the anthropogenic and 
natural contributions to long-term changes in $\mathrm{CO}_{2}$ growthrate. The statistical significance of the trends noted by (Canadell et al., 2007) and Raupach et al. (2008) was challenged by Knorr (2009). Gloor et al. (2010) also pointed out difficulties in interpreting changes in the relationship between emissions and growth-rate in terms of the response of the system. They used a linear perturbation model and developed diagnostics of the airborne fraction from it. We will use the same model but, rather than diagnosing the behaviour of a yet simpler model (airborne fraction) we will use it to diagnose the behaviour of inferred or modelled fluxes from more complex systems.

Along with this controversy over long-term changes in the sink efficiency, different questions have emerged on more recent changes. Sarmiento et al. (2010) used a combination of the atmospheric growth-rate, anthropogenic inputs and an ocean model to posit an abrupt change in the terrestrial uptake around 1988. Francey et al. (2010) and Francey et al. (2013) pointed out that, since the early 2000s, the growthrate of atmospheric $\mathrm{CO}_{2}$ had failed to keep pace with the acceleration in reported fossil fuel use. Their conclusion was to question the timing of this acceleration. ${ }^{1}$

To provide context for subsequent discussions, Fig. 1 plots the history of anthropogenic carbon fluxes and the growthrate in atmospheric $\mathrm{CO}_{2}$. It also shows the predicted growthrate from two simple models to be discussed later. Data is taken from Le Quéré et al. (2013). We see a clear increase in anthropogenic fluxes and a much noisier increase in the atmospheric growth-rate. We also see an increasing divergence between these curves, connoting an increasing uptake. This uptake is a response to a range of perturbations, atmospheric $\mathrm{CO}_{2}$ itself, nutrient input, land management and land-use change and doubtless many others. Here we analyse this uptake as a simple linear response to $\mathrm{CO}_{2}$ concentration. We use $\mathrm{CO}_{2}$ concentration as a surrogate for forcings with a similar time course, that is we do not attempt to separate $\mathrm{CO}_{2}$ forcing of the response from other drivers. Rather we ask whether there has been significant departure from this linear response evident in recent years. Further we analyse regional contributions to this linear response. This provides a simple diagnostic of model responses which can be compared with inverse estimates of regional fluxes. Our focus is on the change of uptake rather than its mean value. Such analysis of trends requires reasonably long records and is hence less certain at regional than global scales.

The outline of the paper is as follows: Sect. 2 describes the simple diagnostics we use and the data. Section 3 analyses the global record in terms of this diagnostic. Section 4 applies the same diagnostic to regional fluxes from inverse estimates while Sect. 5 applies it to terrestrial models. Section 6 points

\footnotetext{
${ }^{1}$ Some confusion has arisen between the two discussions of changes in airborne fraction. In general they address different timescales.
}

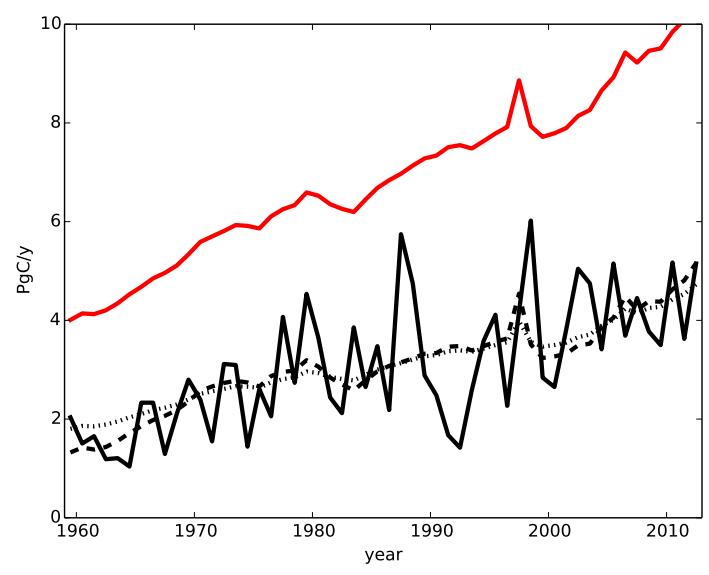

Figure 1. Anthropogenic inputs (red) and atmospheric growth rate (black) from Le Quéré et al. (2013). Anthropogenic inputs include both fossil and land-use. The dotted line shows the predicted atmospheric growth-rate from the airborne fraction model while the dashed line shows the growth-rate from the $\beta$-model.

out some of the caveats and implications in the preceding analysis and Sect. 7 summarizes the main points.

\section{Methods and tools}

\subsection{Defining the carbon budget}

Our aim is to analyse the response of parts of the carbon budget to changes in forcing. We must therefore define which terms of the carbon budget we consider. We start with the decomposition used by the Global Carbon Project (GCP) (Le Quéré et al., 2013)

$$
\frac{\partial M}{\partial t}=F_{\text {fossil }}+F_{\mathrm{LUC}}-F_{\text {land }}-F_{\text {ocean }},
$$

where $M$ is the mass of carbon in the atmosphere, $F_{\mathrm{LUC}}$ is the flux due to land-use change (LUC) and all other fluxes have their usual meanings. Throughout the paper we will talk of uptakes by land and ocean so we have not followed the usual convention of writing fluxes with a single direction (towards the atmosphere or surface).

We will also frequently combine the two anthropogenic fluxes as

$F_{\text {anthro }}=F_{\text {fossil }}+F_{\text {LUC }}$.

Some terms in Eq. (1) are ambiguous, especially the partition between $F_{\mathrm{LUC}}$ and $F_{\text {land. }}$. This point is discussed by Enting et al. (2012). When discussing global budgets we will follow the GCP definitions. The atmospheric inversion studies we draw on do not separate these two fluxes. Globally we will correct $F_{\text {land }}$ by $F_{\text {LUC }}$ from the GCP. When we consider regional budgets we will ascribe changes in the combined flux to $F_{\text {land }}$ and discuss the implications of this approximation. 


\subsection{Two models}

We follow Gloor et al. (2010) in using two models for the change in atmospheric $\mathrm{CO}_{2}$ concentration in response to anthropogenic inputs. The provenance of these two models and the relationship between them is thoroughly described by Gloor et al. (2010) so we will only summarize them here.

\subsubsection{Airborne fraction model}

This expresses the change in the atmospheric mass of carbon as

$\frac{\partial M}{\partial t}=\alpha F_{\text {anthro }}$,

where $\alpha$ is known as the airborne fraction. ${ }^{2}$ Combining this with Eq. (1) we see

$F_{\text {land }}+F_{\text {ocean }}=(1-\alpha) F_{\text {anthro }}$.

It is important to remember that Eq. (4) represents a relationship following from mass conservation rather than a causal relationship between anthropogenic inputs and contemporaneous uptakes. It is hard to conceive a mechanism that would link the three fluxes in Eq. (4).

\subsubsection{The $\beta$-model}

An alternative to the airborne fraction model is to parameterize $\mathrm{CO}_{2}$ uptakes as a linear function of $\mathrm{CO}_{2}$ concentration or, equivalently, $\mathrm{CO}_{2}$ mass (Gloor et al., 2010). Thus we write

$F_{\text {land }}+F_{\text {ocean }}=\beta\left(M-M_{0}\right)$,

where $M$ is the mass of $\mathrm{CO}_{2}$ in the atmosphere and $M_{0}$ is the background or equilibrium mass of $\mathrm{CO}_{2}$ in the atmosphere. Given the near-equilibrium of the preindustrial carbon cycle evident from the data of Etheridge et al. (1996) and Francey et al. (1999) we often use the preindustrial value of $M$ for $M_{0}$. With our focus in this paper on changes rather than mean values we are not interested in $M_{0}$ so we simplify Eq. (5) to

$F_{\text {land }}+F_{\text {ocean }}=\beta M+F_{0}$.

$\beta$ has units of $\mathrm{yr}^{-1}$ and plays the role of an inverse residence time for excess carbon against the processes of land and ocean uptake.

Substituting Eq. (6) into Eq. (1) yields

$\frac{\partial M}{\partial t}=F_{\text {anthro }}-\beta M-F_{0}$.

With independent data available on $F_{\text {anthro }}$ and $M$ it is possible to estimate $\beta$ and $F_{0}$ using standard statistical techniques such as linear regression. Below we apply this technique to

\footnotetext{
${ }^{2}$ Airborne fraction can also be quoted relative to $F_{\text {fossil }}$.
}

flux estimates at several scales and from several sources. Although we consider some aspects of uncertainty in the calculation we have not applied our diagnostics to the ensembles of results available in intercomparisons of forward or inverse models.

\section{Global responses}

In this section we compare the behaviour of the two models introduced in Sect. 2.2. We use the data from the Global Carbon Project (Le Quéré et al., 2013) to estimate $\alpha$ from Eq. (3) and $\beta$ from Eq. (6). Data in Le Quéré et al. (2013) comes from many sources. $M$ (and consequently $\frac{\partial M}{\partial t}$ ) come from concentration measurements of $\mathrm{CO}_{2}$ at South Pole and Mauna Loa before 1980 and a range of marine boundary layer sites thereafter. $F_{\text {fossil }}$ is derived from inventories from the Carbon Dioxide Information Analysis Center. $F_{\text {LUC }}$ and $F_{\text {ocean }}$ come from a combination of inventories and models. $F_{\text {land }}$ is derived as a residual.

We use the standard maximum likelihood least squares formulation so that

$\boldsymbol{x}=\mathbf{K} \mathbf{J}^{\mathrm{T}} \mathbf{R}^{-1} \boldsymbol{y}$,

where $\boldsymbol{x}$ is the vector of unknowns we seek, $\boldsymbol{y}$ the data, $\mathbf{J}$ the Jacobian matrix mapping $\boldsymbol{x}$ to $\boldsymbol{y}$ and $\mathbf{R}$ the uncertainty covariance for $\boldsymbol{y} . \mathbf{K}$ is given by

$\mathbf{K}=\left[\mathbf{J}^{\mathrm{T}} \mathbf{R}^{-1} \mathbf{J}\right]^{-1}$.

After some simplification the uncertainty covariance for $\boldsymbol{x}$ is given by

$\mathbf{C}(\boldsymbol{x})=\mathbf{K}^{-1}$.

For the $\alpha$-model $\mathbf{J}=F_{\text {anthro }}$ and $\boldsymbol{y}=\frac{\partial M}{\partial t}$ while for the $\beta$ model $\mathbf{J}={ }_{M}^{1}$ and $\boldsymbol{y}=F_{\text {anthro }}-\frac{\partial M}{\partial t}$. For the $\beta$-model we include a constant term in the inversion (see Eq. 5). This is mathematically the uptake when $M=0$. Physically it represents uptakes which do not vary with $M$, e.g. those caused by reforestation. It also contributes to the mean uptake over a period. We stress that we are not here concerned with the mean uptake over the whole or part of the study period.

For $\mathbf{R}$ there are two contributions, data uncertainties and modelling errors. The uncertainties in $\boldsymbol{y}$ are quoted in Le Quéré et al. (2013) as $5 \%$ for $F_{\text {fossil }}, 0.5 \mathrm{PgC} \mathrm{yr}^{-1}$ for $F_{\mathrm{LUC}}$ and 0.7 or $0.2 \mathrm{PgCyr}^{-1}$ for $\frac{\partial M}{\partial t}$ before or after 1970. We add these quadratically. Growth-rate uncertainty dominates before 1970 while $F_{\text {LUC }}$ is the largest contributor later. The root mean square value of the uncertainty is $0.69 \mathrm{PgC} \mathrm{yr}^{-1}$. The errors due to the simplicity of the models can only be calculated once we have performed the fit.

Le Quéré et al. (2013) did not give clear guidance on temporal correlation for their uncertainties. The most likely form 
for these is positive temporal correlation arising from systematic errors in reporting or biogeochemical models. Our analysis is concerned with trends, that is of year-to-year differences. Positive temporal correlations will increase the significance of these trends. Thus we make the conservative assumption of temporal independence. The one case where this is not true we will treat explicitly.

Figure 1 also shows the observed and predicted atmospheric growth-rate from the two models. The regression solutions give $\alpha=0.45$ and $\beta=0.016 \mathrm{yr}^{-1}$. The two models produce mean-square residuals of $0.95 \mathrm{PgC} \mathrm{yr}^{-1}$. Thus we use this value as the uncertainty $\mathbf{R}$ for the dependent variable in the regression for the $\beta$-model. It yields a $1 \sigma$ uncertainty of $0.002 \mathrm{yr}^{-1}$. Calculating the uncertainty of $\alpha$ is more difficult since the most uncertain term is the Jacobian. We can approximate it by noting that the relationship between $F_{\text {anthro }}$ and $\frac{\partial M}{\partial t}$ can be integrated to give $M_{\text {final }}-M_{\text {initial }}=$ $\alpha \sum F_{\text {anthro }}$. The total change of $\mathrm{CO}_{2}$ mass in the atmosphere is constrained by the initial and final concentration uncertainties and these concentrations are very well known. Thus the percentage error in $\alpha$ is the percentage error in $\sum F_{\text {anthro }}$. The uncertainty in $\sum F_{\text {anthro }}$ can be calculated for the limiting cases of complete independence and perfect temporal correlation. For the independent case we sum uncertainties quadratically to give $4.3 \mathrm{PgC}$ of a total of $372 \mathrm{PgC}$, or about $1 \%$ uncertainty. For the case of perfect correlation the $5 \%$ uncertainty in annual values translates to a $5 \%$ uncertainty in the total. Thus the uncertainty in $\alpha$ lies between $1 \%$ and $5 \%$.

Figure 2 shows the residuals from the $\alpha$ and $\beta$ models from Fig. 1. The two models produce similar residuals. Both residuals are driven by short-term changes in the atmospheric growth-rate and arise from the failure of these simple integrated models to reproduce such changes. One striking similarity is the increase in the amplitude of the residuals with time. The amplitudes grow by $60 \%$ from the first to the second half of the period. The interannual variability has been used by Cox et al. (2013) and Wang et al. (2014) to assess the sensitivity of the carbon cycle to forcing.

By construction, $\beta$ provides an optimal fit to the time course of $\frac{\partial M}{\partial t}$ but this does not mean it is optimal throughout. We can ask whether different periods suggest different magnitudes for $\beta$. Here we focus on the 11-year period 2002-2012. We repeat the calculation, obtaining $\beta=$ $0.057 \pm 0.018 \mathrm{yr}^{-1}$. This is much larger but much more uncertain than the overall value of $\beta=0.016 \pm 0.002 \mathrm{yr}^{-1}$. The large $\beta$ value is a direct result of the negative trend in the residuals evident from 2002. The difference can be considered statistically significant with a $5 \%$ probability of a larger value occurring by chance over this period. We can also ask whether it is robust, that is how sensitive is the result to our choice of period. We repeat the analysis for every 11-year period in the record (i.e starting with 1959, 1960 etc). This yields 6 values greater than $0.057 \mathrm{yr}^{-1}$.

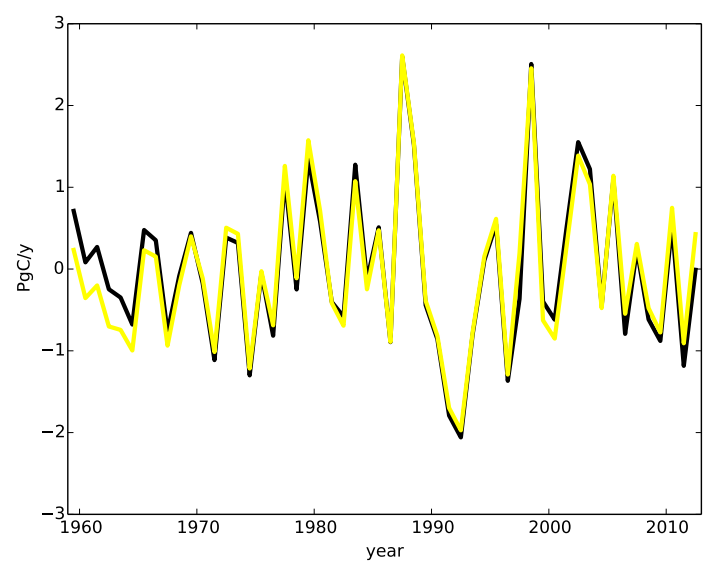

Figure 2. Residuals in the growth rate (observed - predicted) for the $\alpha$ model (yellow) and $\beta$ model (black).

We can also ask whether the mean residual of the fit of the $\beta$-model is significantly different from 0 . The mean residual for 2002-2012 is $-0.07 \pm 0.27 \mathrm{Pg} \mathrm{Cyr}^{-1}$. The large error bar is a result of the large interannual variability. In summary, the mean $\mathrm{CO}_{2}$ uptake over the last decade is not significantly different from that predicted by a linear response to concentration. The change in trend over that time is approaching significance but is not robust. Let us now analyse some spatially resolved estimates of fluxes to try to attribute the behaviour over the full period and more recently.

\subsection{Land and ocean contributions}

One useful property of Eq. (6) is that, if we can decompose fluxes as $F=F_{1}+F_{2}+\ldots$ we can decompose the corresponding $\beta$ values as $\beta=\beta_{1}+\beta_{2}+\ldots$. We will show decompositions into land or ocean, by latitude band and by season. In each case we replace $\boldsymbol{y}$ in Eq. 8 with the corresponding flux.

First we calculate $\beta$ for land and ocean separately using the values and uncertainties from Le Quéré et al. (2013). The uncertainties are $0.5 \mathrm{PgCyr}^{-1}$ for the ocean and $0.8 \mathrm{Pg} \mathrm{Cyr}^{-1}$ for the land. We obtain $\beta=0.010 \pm 0.001 \mathrm{yr}^{-1}$ for ocean and $\beta=0.006 \pm 0.002 \mathrm{yr}^{-1}$ for land. The root mean square residuals are $0.18 \mathrm{PgCyr}^{-1}$ for ocean and $0.96 \mathrm{PgC} \mathrm{yr}^{-1}$ for land. The calculated residuals for land have a larger magnitude than assumed which suggests we should increase the land $\beta$ uncertainty to $0.003 \mathrm{yr}^{-1}$.

Figure 3 shows the GCP estimates and the linear fits. When analysing these we must remember that the GCP land estimate is calculated as a residual from Eq. (1). The relatively small residuals from the ocean fit and the additive form of the $\beta$ decomposition imply that the residuals in the land uptake resemble those in the total uptake.

Again considering the period 2002-2012 we obtain $0.047 \mathrm{yr}^{-1}$ for land and $0.01 \mathrm{yr}^{-1}$ for ocean. As with the total uptake, there are 6 periods of 11 years with larger $\beta$ for 


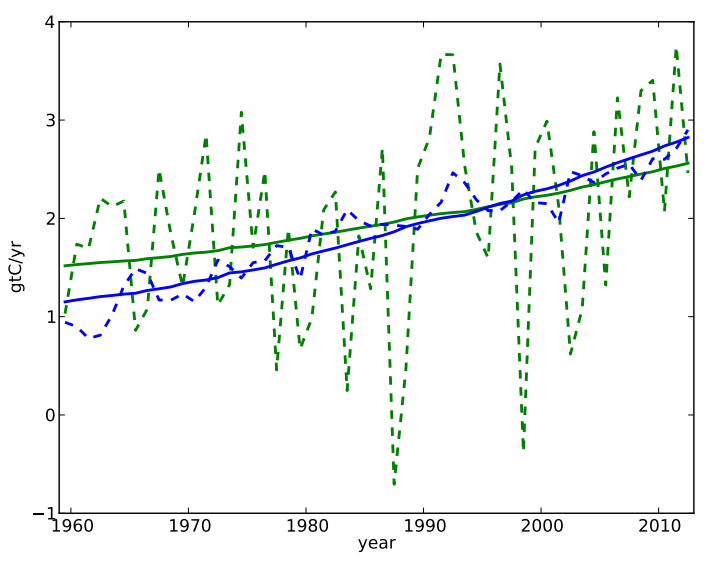

Figure 3. Ocean uptake (blue) and land uptake (green) in $\mathrm{PgC}_{\mathrm{yr}}{ }^{-1}$. Dashed lines are estimates from Le Quéré et al. (2013) while the solid lines are predictions from the $\beta$ model.

the land while the ocean value is at the mean and median for the set of 11-year periods. Thus even when accounting for the different interannual variability of each environment the relative changes in the land flux are much larger than for the ocean. Changes in land uptake explain all the increase in total uptake over 2002-2012 but this change cannot be regarded as robust.

\section{Diagnostics for inversions}

We can further decompose land and ocean fluxes into their regional contribution and calculate the related $\beta$ to attribute regional contributions to trends. Regional flux estimates can come either from atmospheric inversions or models. In this section we use an update of the Cubic Conformal Atmospheric Model (CCAM) inversion used in Peylin et al. (2013) which extended the study of Rayner et al. (2008). The update extends the study period from 1992-2012. Rayner et al. (2008) required that stations must report measurements during $70 \%$ of months in their study period in order to be included. We apply the same criterion but the different study period means the network will be different from that of Rayner et al. (2008). The ${ }^{13} \mathrm{CO}_{2}$ records are also extended to 2012. Calculations for the data uncertainties are as in Rayner et al. (2008). We use only the CCAM model from the earlier study.

Before we can trust the inversion to identify regional changes we verify its ability to match the atmospheric growth-rate. This is best done by comparing the net, nonfossil flux. For the GCP this is the sum of the LUC, land and ocean fluxes while for the inversion it is the annual mean, non-fossil flux. We are interested in variability so we adjust the GCP and inverse mean fluxes to be equal for plotting purposes. The inclusion of the constant term in Eq. 5 means this will have no effect on the calculated $\beta$. Figure 4 shows the
Table 1. Land and ocean $\beta$ values from the GCP budget and inversion for the periods 1992-2012 and 2002-2012.

\begin{tabular}{lcccc}
\hline Flux & \multicolumn{2}{c}{$\begin{array}{c}\text { 1992-2012 } \\
\text { uncertainty } \mathrm{yr}^{-1}\end{array}$} & $\beta \mathrm{yr}^{-1}$ & $\begin{array}{c}\text { 2002-2012 } \\
\text { uncertainty } \mathrm{yr}^{-1}\end{array}$ \\
\hline Inversion land & 0.025 & 0.007 & 0.050 & 0.017 \\
GCP land & 0.017 & 0.005 & 0.056 & 0.015 \\
Inversion ocean & 0.003 & 0.005 & 0.014 & 0.012 \\
GCP ocean & 0.008 & 0.005 & 0.009 & 0.011 \\
\hline
\end{tabular}

results for the GCP and inversion. As we would hope we see good agreement for both short and long term variability. We stress that this is a necessary but not sufficient condition for successful regionalization of trends.

Next we can ask whether the GCP and inversion agree on the land-ocean division of recent sink changes. Table 1 presents the results for the inversion and GCP budget for the periods 1992-2012 and 2002-2012. For comparison we calculate the net land flux for the GCP as the difference between LUC and land uptake. Similarly we calculate the uncertainty here from the residual budget between the growth rate, fossil fuel flux and ocean uptake. Most $\beta$ values agree to within their uncertainties. We see general agreement on the predominance of land over ocean responses and the much stronger response over 2002-2012. Thus, as far as we can tell from independent evidence, the inversion is partitioning reasonably the linear responses of land and ocean. We stress that this was not preordained since the ocean models which control the trend in land-ocean partition for the GCP estimates do not inform the inversion. We can proceed to discuss the regional form of these responses.

Figure 5 shows the estimated flux and fit from the $\beta$ model for land and ocean and northern extratropics, tropics and southern extratropics separately. The groupings are taken from Gurney et al. (2002) rather than a latitudinal separation. This allows us to calculate the uncertainty of the regional fluxes correctly. The uncertainties used in the $\beta$-model fit are the generated annual uncertainties from the posterior covariance of the inversion. Results of the fit are shown in Table 2 for 1992-2012 and 2002-2012. Both Fig. 5 and Table 2 show strong spatial patterns in the linear response of uptake.

As one might expect from the small global $\beta$ for the ocean, most ocean regions show weak response and, given their uncertainties, none could be reliably distinguished from 0 . One exception is the southern extratropical ocean for 2002-2012. The large uncertainties counsel caution but the apparent increase in the response does not support findings of long-term reductions in uptake (e.g. Le Quere et al., 2009). This is in line with the results of Law et al. (2008).

For land, there is a strong positive response of uptake in the northern extratropics and near cancellation between the tropics and southern extratropics. The tropics shows a large negative $\beta$ over the whole period. The tropical $\beta$ depends strongly on the changes in $F_{\text {LUC }}$. This is particularly evident 


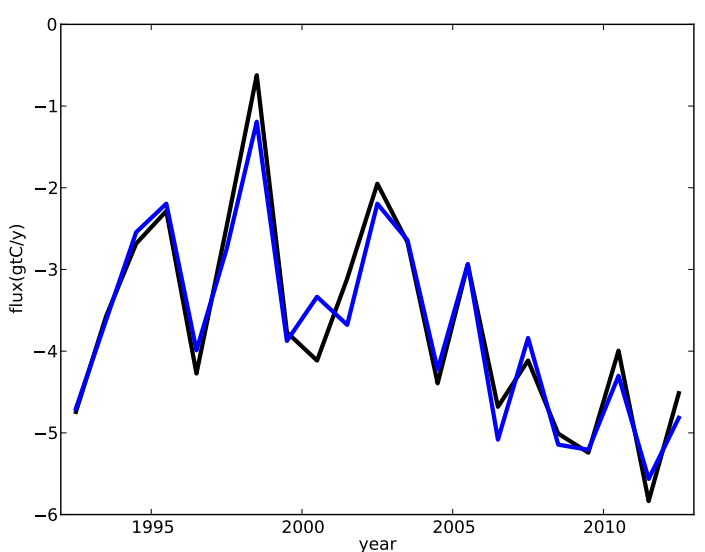

Figure 4. Net uptake from Le Quéré et al. (2013) (black) and from the inversion (blue). Means over the period have been adjusted to be equal.

for 2002-2012 where the increase in $\beta$ is coincident with a sharp downward trend in $F_{\mathrm{LUC}}$. Any error in trends of $F_{\mathrm{LUC}}$ will be aliased into the calculated $\beta$. The dipole in response between the tropics and southern extratropics raises the possibility of highly uncertain responses with strong error correlations. This was certainly the case for the mean flux noted by Jacobson et al. (2007) who reported large uncertainty correlations between these regions in atmospheric inversions.

The response with the largest signal-noise occurs in the northern extratropical land. The response is large over the whole period and much larger for 2002-2012 where it dominates the global signal. The increase in relative uncertainty as we move to smaller regions precludes a more detailed spatial examination of the signal. The results suggest that, notwithstanding the cautionary finding of Piao et al. (2008), the strong trend in greenness (e.g. Zhou et al., 2001; Xu et al., 2013) has made a strong imprint on the pattern of $\mathrm{CO}_{2}$ uptake.

We can further decompose the $\beta$ for the northern extratropical land into the positive and negative components of the flux. The growing season net flux (GSNF) is defined as the sum of all the negative (uptake) components over a year. We further define the quiescent season net flux (QSNF) as the sum of all the positive (source) fluxes. The annual uptake can be decomposed as annual flux $=$ GSNF - QSNF and thus $\beta$ can be decomposed as

$\beta_{\mathrm{annual}}=\beta_{\mathrm{GSNF}}-\beta_{\mathrm{QSNF}}$

The term $\beta_{\mathrm{GSNF}}+\beta_{\mathrm{QSNF}}$ reflects a change in the integrated amplitude of the seasonal flux and hence to a likely change in the seasonal amplitude of concentration. These changes in amplitude have been noted by Keeling et al. (1995) and Graven et al. (2013) in surface and airborne measurements in the Northern Hemisphere. Roughly paraphrased, the argument of Piao et al. (2008) is that near cancellation between
Table 2. Land and ocean $\beta$ values from the inversion for northern extratropics, tropics and southern extratropics for the periods 19922012 and 2002-2012.

\begin{tabular}{lrcrc}
\hline Flux & \multicolumn{2}{c}{$\begin{array}{c}\text { 1992-2012 } \\
\text { uncertainty } \mathrm{yr}^{-1}\end{array}$} & \multicolumn{1}{c}{$\beta \mathrm{yr}^{-1}$} & $\begin{array}{c}\text { 2002-2012 } \\
\text { uncertainty yr }\end{array}$ \\
& \multicolumn{1}{c}{$\beta \mathrm{yr}^{-1}$} & 0.037 & 0.012 \\
Northern land & 0.015 & 0.005 & -0.004 & 0.005 \\
Northern ocean & 0.002 & 0.002 & 0.002 & 0.021 \\
Tropical land & -0.014 & 0.008 & 0.002 & 0.006 \\
Tropical ocean & 0.001 & 0.003 & 0.017 & 0.016 \\
Southern land & 0.009 & 0.007 & 0.007 & 0.007 \\
Southern ocean & 0.001 & 0.003 & 0.034 & 0.069 \\
\hline Northern GSNF & 0.014 & 0.027 & -0.003 & 0.024 \\
Northern QSNF & -0.001 & 0.009 & 0.014 & 0.060 \\
Southern GSNF & 0.010 & 0.023 & 0.003 & 0.039 \\
Southern QSNF & -0.002 & 0.015 & 0.037 & 0.067 \\
Northern max & 0.013 & 0.027 & 0.018 & 0.067 \\
Southern max & 0.007 & 0.027 & & \\
\hline
\end{tabular}

$\beta_{\mathrm{GSNF}}$ and $\beta_{\mathrm{QSNF}}$ means that changes in amplitude need not (and probably do not) correspond to changes in net flux.

Temporally decomposed $\beta$ values for northern and southern extratropical land are also listed in Table 2. As might be expected, the uncertainties on seasonal fluxes are considerably larger than their annual means so again some caution is suggested in interpreting these values. We see a large response in the GSNF but not in the QSNF. We can hence say that the response in net flux is due to the productive part of the year but it is still a step to say the response is related to production since atmospheric inversions sense only the net flux which is always the difference between production and respiration. One further clue to the likely driver is given by a similar analysis for the maximum uptake in each year. The uncertainties are even larger here but we do see similar increases for the maximum as for the GSNF. This suggests that it is the productivity which mediates the linear response in the net flux and its change over time and that this change in productivity is the likeliest cause of the increasing annual uptake in the northern extratropics.

\section{An example of model responses}

If the linear diagnostic is a reasonable way to summarize the behaviour of the large-scale carbon cycle we can also apply it to models. This has the further advantage that we can create process diagnostics the same way. As examples, we analyse the linear response of the LPJ-GUESS model (Smith et al., 2001) and the LPJ model (Sitch et al., 2003). LPJ combines mechanistic treatment of terrestrial ecosystem structure (vegetation composition, biomass) and function (energy absorption, carbon cycling). Vegetation dynamics are updated annually based on the productivity, disturbance, mortality, and establishment of nine plant functional types (PFTs). Modelled potential vegetation cover (including C3-/C4-plant distribution) depends on competition and climate history. LPJ-GUESS' process formulation of plant physiology and 

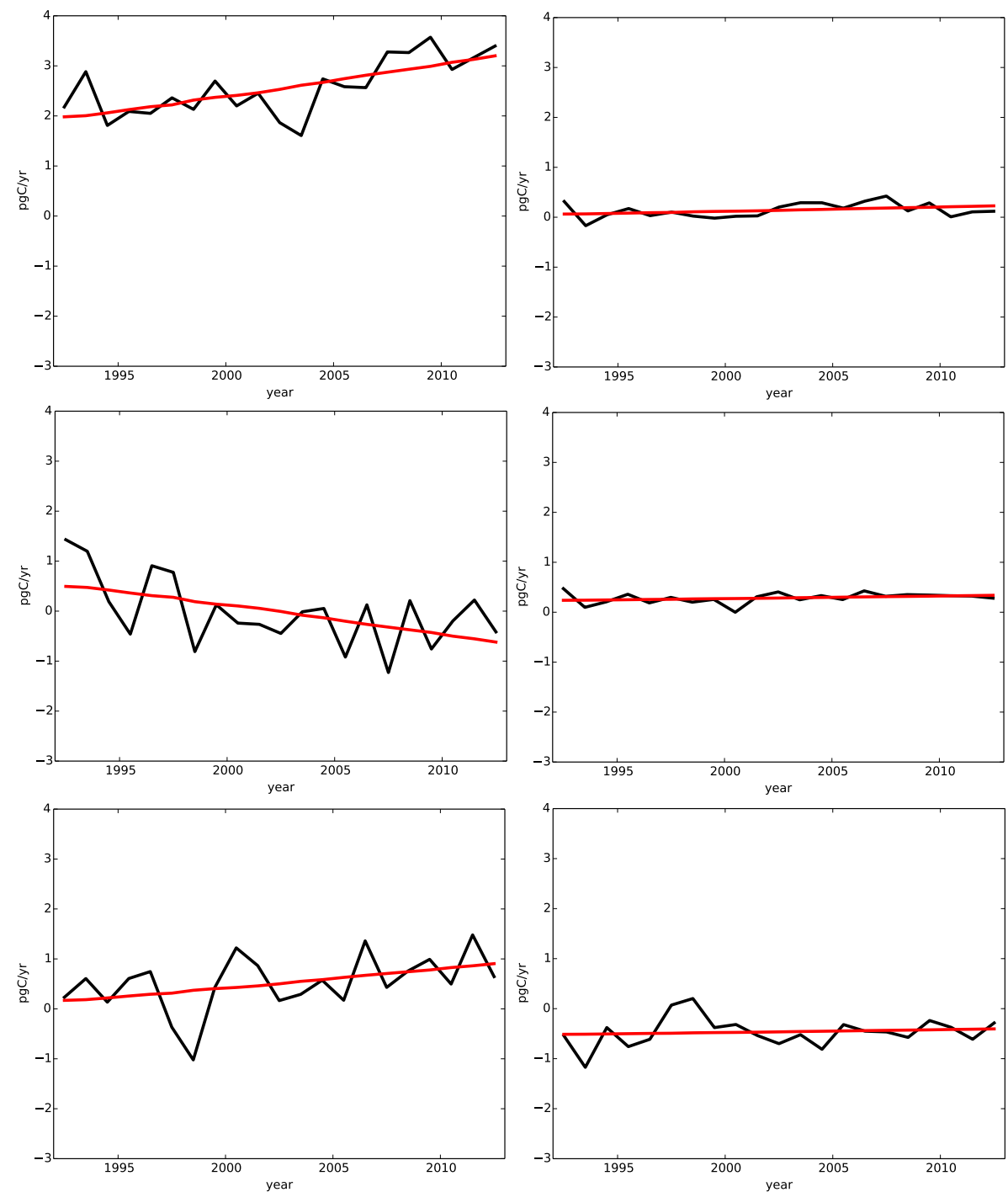

Figure 5. Estimated uptake from inversion (black) and $\beta$-model fit (red) for the north (top row), tropics (middle) and south (bottom) with land on the left and ocean on the right.

ecosystem biogeochemistry is similar to LPJ. However, in contrast to the area-based representation of vegetation structure and dynamics for mean individual plant types of LPJ, LPJ-GUESS employs a more detailed scheme that distinguishes woody plant type individuals (cohorts) and represents patch-scale heterogeneity. LPJ-GUESS explicitly models resource competition (light and water) and subsequent growth between woody plant type individuals on a number of replicate patches. Similar to LPJ, herbaceous under-storey (simulated using the grass PFT) is modelled, but individuals are not distinguished. While the LPJ simulation used here represents potential natural vegetation, LPJ-GUESS takes into account present day land use by accounting for croplands and pastures as grass PFT using the 2005 cropland and pasture map from the Hyde 3.1 database (Klein Goldewijk et al., 2011). Both LPJ and LPJ-GUESS use fixed land cover so we fit the $\beta$-model to the output directly rather than correcting with $F_{\text {LUC }}$.

First we compare the global fluxes for the two models with $F_{\text {land }}$ from the GCP. Figure 6 shows the three fluxes with means adjusted to agree with $F_{\text {land }}$. We see that LPJ agreement is poor for the first half of the period but improves considerably after 1980 . The two models do comparably well in this period.

We have fluxes computed until 2011 for LPJ and 2010 for LPJ-GUESS so we analyse the longest possible period for each model for the closest comparison with the inversion. The $\beta$ values for land in the northern semi-hemisphere, tropics and southern semi-hemisphere are listed in Table 3. We note that we cut the regions at $30^{\circ}$ here rather than the more complex boundaries from Gurney et al. (2002) used in the inversion. We see reasonable agreement for the global $\beta$ for 
Table 3. Global and regional $\beta$ values for the LPJ and LPJ-GUESS models along with the GCP land estimates.

\begin{tabular}{|c|c|c|c|c|}
\hline \multirow[t]{2}{*}{ Flux } & \multicolumn{2}{|c|}{$1992-2010 / 11$} & \multicolumn{2}{|c|}{$2002-2010 / 11$} \\
\hline & $\beta \mathrm{yr}^{-1}$ & uncertainty $\mathrm{yr}^{-1}$ & $\beta \mathrm{yr}^{-1}$ & uncertainty $\mathrm{yr}^{-1}$ \\
\hline LPJ global & 0.020 & 0.020 & 0.139 & 0.055 \\
\hline LPJ-GUESS global & 0.020 & 0.020 & 0.051 & 0.063 \\
\hline GCP land & 0.015 & 0.020 & 0.13 & 0.055 \\
\hline LPJ northern & -0.010 & 0.020 & -0.014 & 0.055 \\
\hline LPJ-GUESS northern & -0.001 & 0.022 & 0.010 & 0.064 \\
\hline LPJ tropics & 0.038 & 0.020 & 0.140 & 0.055 \\
\hline LPJ-GUESS tropics & 0.032 & 0.022 & 0.066 & 0.064 \\
\hline LPJ south & -0.004 & 0.020 & 0.027 & 0.055 \\
\hline LPJ-GUESS south & -0.005 & 0.022 & -0.000 & 0.064 \\
\hline
\end{tabular}

the whole period but only LPJ shows the dramatic increase in the second half of the period.

The regional structure of the linear response in both models is quite different from that suggested by the inversions. Model responses are dominated by the tropics as is the intensification in response in the last decade. This strong positive response is offset by smaller negative responses in the extratropics. The inversion suggests positive responses in the extratropics (especially the north) with ambiguous response in the tropics.

\section{Discussion}

It is tempting to compare our $\beta$ values with those of Gloor et al. (2010). The important difference is that Gloor et al. (2010) do not include a constant term in their linear model (their Eq. 2) while we do. This means their value of $\beta$ ( $\tau_{S}$ in their formulation) will attempt to fit the mean value of uptake while ours will not. Given the likely role of other processes in uptake we would expect that our $\beta$ value would underestimate mean uptake if used without the mean term. This, indeed, is the case with a mean uptake for 1959-2010 of $2.3 \mathrm{yr}^{-1}$ compared to the GCP value of $3.8 \mathrm{yr}^{-1}$. Gloor et al. (2010) predict an uptake of $3.5 \mathrm{yr}^{-1}$. We stress that the formulation of Gloor et al. (2010) is valid for their purposes but that our focus made it important to separate the mean and trends.

We have analysed the $\mathrm{CO}_{2}$ uptake throughout as a linear response to concentration. We have not, however, proposed a causal link with $\mathrm{CO}_{2}$ concentration itself since there are many other variables (e.g. time, temperature and LUC) which are highly colinear with $\mathrm{CO}_{2}$ concentration. The record, especially of regionally resolved fluxes, is not long enough compared to the various exponential doubling times of emission and concentration to allow a clear separation between linear and exponential changes. The evidence from the inversion of a deepening of the growing season flux minimum does suggest a role for productivity. Given the mechanistic link between productivity and concentration this does suggest increasing concentration changes have contributed to increased land uptake. The two ecosystem models we studied

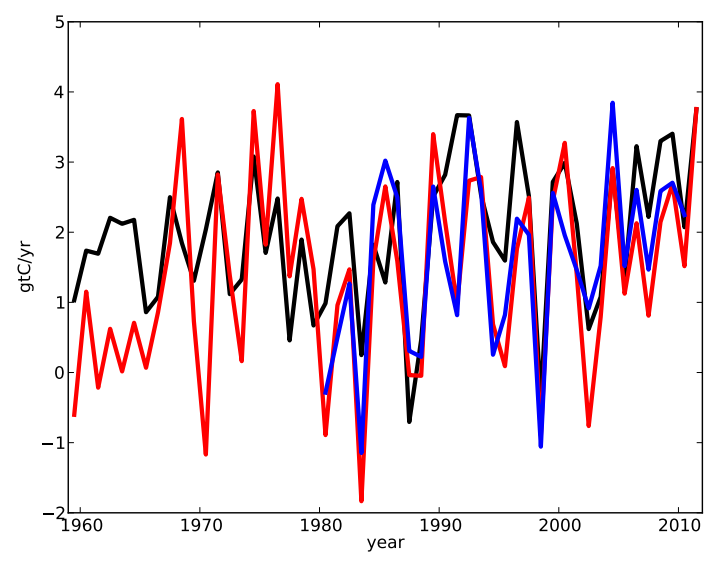

Figure 6. Terrestrial uptakes from Le Quéré et al. (2013) (black), LPJ (red) and LPJ-GUESS (blue). Means have been adjusted to give equal uptake over the whole period.

are too dissimilar in their responses to the inversion to use them as a diagnostic of the inferred flux behaviour.

The results for the most recent decade suggest a strong, but not yet robust increase in the linear response. It suggests that if there is a change in carbon-cycle behaviour, it is in a direction to mitigate rather than exacerbate climate change. We note the much weaker response of tropical uptake and the sensitivity of our result to $F_{\text {LUC }}$ estimates.

Finally, the linear diagnostic suggests an interesting interpretation for the recent result of Wang et al. (2014). They noted a large increase in the interannual variability of the terrestrial carbon cycle over the second half of the GCP period. We noted the same thing when considering the residuals from our linear fit. While it is tempting to interpret this increase as an increase in the climate sensitivity of the carbon cycle it seems equally possible that it is a constant modulation of a more strongly forced process. As an analogy we may consider a container with a tap at the bottom which is being randomly opened and closed. The variation in flow will increase as the height of water in the container increases even if the variation in the tap is unchanged. A weakness in this argument is the difference between the location of peak variability (usually located in the tropical land) and the dominant response (located by the inversion in the extratropics).

The calculations in this paper are mainly exemplary. We have made little attempt yet to see how robust the findings are across different terrestrial models and inverse systems. The first of these is relatively easy, aided by several intercomparisons which collect model output. The specification of uncertainty is difficult for models however. For inversions the difficulty is to isolate the components of the flux which are legitimate targets for these diagnostics. $F_{\text {LUC }}$ is often included in inverse models as part of the prior flux and it must be separated. Similarly, with an in-house inversion system it is possible to calculate uncertainty on the same scale as the flux estimates while this information is often not available 
for data from intercomparisons such as that of Peylin et al. (2013). That said, these diagnostics do seem a simple way of summarizing longer-term behaviour of any flux estimate. It will be interesting to see if the finding of Baker et al. (2006) that interannual variability in flux is more robust across the model ensemble than the mean flux also holds for these longterm changes.

\section{Conclusions}

We have characterized the global and regional response of the carbon cycle as a linear response to $\mathrm{CO}_{2}$ concentration (or any colinear variable). We have seen that this fit works as well as the airborne fraction model with the advantage that it can be decomposed by time and space. We see an increase in the linear global response in recent years dominated by land. Inverse flux estimates show a similar response and locate it in the northern extratropics and the growing season. Terrestrial ecosystem models show a similar global response but, by contrast, locate it in the tropics.

Acknowledgements. P. J. Rayner is in receipt of an Australian Professorial Fellowship (DP1096309). This research was undertaken on the NCI National Facility in Canberra, Australia, which is supported by the Australian Commonwealth Government.

Edited by: A. Michalak

\section{References}

Baker, D. F., Law, R. M., Gurney, K. R., Rayner, P., Peylin, P., Denning, A. S., Bousquet, P., Bruhwiler, L., Chen, Y.-H., Ciais, P., Fung, I. Y., Heimann, M., John, J., Maki, T., Maksyutov, S., Masarie, K., Prather, M., Pak, B., Taguchi, S., and Zhu, Z.: TransCom 3 inversion intercomparison: impact of transport model errors on the interannual variability of regional $\mathrm{CO}_{2}$ fluxes, 1988-2003, Global Biogeochem. Cy., 20, GB1002, doi:10.1029/2004GB002439, 2006.

Canadell, J. G., Le Quéré, C., Raupach, M. R., Field, C. B., Buitenhuis, E. T., Ciais, P., Conway, T. J., Gillett, N. P., Houghton, R. A., and Marland, G.: Contributions to accelerating atmospheric $\mathrm{CO}_{2}$ growth from economic activity, carbon intensity, and efficiency of natural sinks, P. Natl. Acad. Sci. USA, 104, 18866-18870, doi:10.1073/pnas.0702737104, 2007.

Cox, P. D., Betts, R. A., Jones, C. D., Spall, S. A., and Totterdell, I. J.: Acceleration of global warming due to carbon-cycle feedbacks in a coupled climate model, Nature, 408, 184-187, 2000.

Cox, P. M., Pearson, D., Booth, B. B., Friedlingstein, P., Huntingford, C., Jones, C. D., and Luke, C. M.: Sensitivity of tropical carbon to climate change constrained by carbon dioxide variability, Nature, 494, 341-344, 2013.

Enting, I. G., Rayner, P. J., and Ciais, P.: Carbon Cycle Uncertainty in REgional Carbon Cycle Assessment and Processes (REC-
CAP), Biogeosciences, 9, 2889-2904, doi:10.5194/bg-9-28892012, 2012.

Etheridge, D. M., Steele, L. P., Langenfelds, R. L., Francey, R. J., Barnola, J. M., and Morgan, V. I.: Natural and anthropogenic changes in atmospheric $\mathrm{CO}_{2}$ over the last 1000 years from air in Antarctic ice and firn, J. Geophys. Res., 101, 4115-4128, 1996.

Francey, R. J., Allison, C. E., Etheridge, D. M., Trudinger, C. M., Enting, I. G., Leuenberger, M., Langenfelds, R. L., Michel, E., and Steele, L. P.: A 1000-year high precision record of $\delta^{13} \mathrm{C}$ in atmospheric $\mathrm{CO}_{2}$, Tellus B, 51, 170-193, 1999.

Francey, R. J., Trudinger, C. M., Van Der Schoot, M., Krummel, P. B., Steele, L. P., and Langenfelds, R. L.: Differences between trends in atmospheric $\mathrm{CO}_{2}$ and the reported trends in anthropogenic $\mathrm{CO}_{2}$ emissions, Tellus $\mathrm{B}, 62,316-328$, doi:10.1111/j.1600-0889.2010.00472.x, 2010.

Francey, R. J., Trudinger, C. M., van der Schoot, M., Law, R. M., Krummel, P. B., Langenfelds, R. L., Paul Steele, L., Allison, C. E., Stavert, A. R., Andres, R. J., and Rodenbeck, C.: Atmospheric verification of anthropogenic $\mathrm{CO}_{2}$ emission trends, Nature Clim. Change, 3, 520-524, doi:10.1038/nclimate1817, 2013.

Friedlingstein, P., Cox, P., Betts, R., Bopp, L., von Bloh, W., Brovkin, V., Doney, S., Eby, M., Fung, I., Govindasamy, B., John, J., Jones, C., Joos, F., Kato, T., Kawamiya, M., Knorr, W., Lindsay, K., Matthews, H. D., Raddatz, T., Rayner, P., Reick, C., Roeckner, E., Schnitzler, K.-G., Schnur, R., Strassmann, K., Thompson, S., Weaver, A. J., Yoshikawa, C., and Zeng, N.: Climate -carbon cycle feedback analysis, results from the C4MIP model intercomparison, J. Climate, 19, 3737-3753, 2006.

Gloor, M., Sarmiento, J. L., and Gruber, N.: What can be learned about carbon cycle climate feedbacks from the $\mathrm{CO}_{2}$ airborne fraction?, Atmos. Chem. Phys., 10, 7739-7751, doi:10.5194/acp10-7739-2010, 2010.

Graven, H. D., Keeling, R. F., Piper, S. C., Patra, P. K., Stephens, B. B., Wofsy, S. C., Welp, L. R., Sweeney, C., Tans, P. P., Kelley, J. J., Daube, B. C., Kort, E. A., Santoni, G. W., and Bent, J. D.: Enhanced seasonal exchange of $\mathrm{CO}_{2}$ by northern ecosystems since 1960 , Science, 341, 1085-1089, doi:10.1126/science.1239207, 2013.

Gurney, K. R., Law, R. M., Denning, A. S., Rayner, P. J., Baker, D., Bousquet, P., Bruhwiler, L., Chen, Y.-H., Ciais, P., Fan, S., Fung, I. Y., Gloor, M., Heimann, M., Higuchi, K., John, J., Maki, T., Maksyutov, S., Masarie, K., Peylin, P., Prather, M., Pak, B. C., Randerson, J., Sarmiento, J., Taguchi, S., Takahashi, T., and Yuen, C.-W.: Towards robust regional estimates of $\mathrm{CO}_{2}$ sources and sinks using atmospheric transport models, Nature, 415, 626-630, 2002.

Jacobson, A. R., Mikaloff Fletcher, S. E., Gruber, N., Sarmiento, J. L., and Gloor, M.: A joint atmosphereocean inversion for surface fluxes of carbon dioxide: 2 . Regional results, Global Biogeochem. Cy., 21, GB1020, doi:10.1029/2006GB002703, 2007.

Keeling, C. D., Whorf, T. P., Wahlen, M., and van der Plicht, J.: Interannual extremes in the rate of rise of atmospheric carbon dioxide since 1980, Nature, 375, 666-670, 1995.

Klein Goldewijk, K., Beusen, A., van Drecht, G., and de Vos, M.: The HYDE 3.1 spatially explicit database of human-induced global land-use change over the past 12000 years, Global Ecol. 
Biogeogr., 20, 73-86, doi:10.1111/j.1466-8238.2010.00587.x, 2011.

Knorr, W.: Is the airborne fraction of anthropogenic $\mathrm{CO}_{2}$ emissions increasing?, Geophys. Res. Lett., 36, L21710, doi:10.1029/2009GL040613, 2009.

Law, R. M., Matear, R. J., and Francey, R. J.: Comment on Saturation of the Southern Ocean $\mathrm{CO}_{2}$ Sink Due to Recent Climate Change, Science, 319, 570, doi:10.1126/science.1149077, 2008.

Le Quéré, C., Rödenbeck, C., Buitenhuis, E. T., Conway, T. J., Langenfelds, R., Gomez, A., Labuschagne, C., Ramonet, M., Nakazawa, T., Metzl, N., Gillett, N., and Heimann, M.: Saturation of the Southern Ocean $\mathrm{CO}_{2}$ sink due to recent climate change, Science, 316, 1735-1738, doi:10.1126/science.1136188, 2007.

Le Quere, C., Raupach, M. R., Canadell, J. G., Marland, G., Bopp, L., Ciais, P., Conway, T. J., Doney, S. C., Feely, R. A., Foster, P., Friedlingstein, P., Gurney, K., Houghton, R. A., House, J. I., Huntingford, C., Levy, P. E., Lomas, M. R., Majkut, J., Metzl, N., Ometto, J. P., Peters, G. P., Prentice, I. C., Randerson, J. T., Running, S. W., Sarmiento, J. L., Schuster, U., Sitch, S., Takahashi, T., Viovy, N., van der Werf, G. R., and Woodward, F. I.: Trends in the sources and sinks of carbon dioxide, Nat. Geosci., 2, 831-836, doi:10.1038/ngeo689, 2009.

Le Quéré, C., Peters, G. P., Andres, R. J., Andrew, R. M., Boden, T. A., Ciais, P., Friedlingstein, P., Houghton, R. A., Marland, G., Moriarty, R., Sitch, S., Tans, P., Arneth, A., Arvanitis, A., Bakker, D. C. E., Bopp, L., Canadell, J. G., Chini, L. P., Doney, S. C., Harper, A., Harris, I., House, J. I., Jain, A. K., Jones, S. D., Kato, E., Keeling, R. F., Klein Goldewijk, K., Körtzinger, A., Koven, C., Lefèvre, N., Maignan, F., Omar, A., Ono, T., Park, G.-H., Pfeil, B., Poulter, B., Raupach, M. R., Regnier, P., Rödenbeck, C., Saito, S., Schwinger, J., Segschneider, J., Stocker, B. D., Takahashi, T., Tilbrook, B., van Heuven, S., Viovy, N., Wanninkhof, R., Wiltshire, A., and Zaehle, S.: Global carbon budget 2013, Earth Syst. Sci. Data, 6, 235-263, doi:10.5194/essd-6-235-2014, 2014.

Nabuurs, G.-J., Lindner, M., Verkerk, P. J., Gunia, K., Deda, P., Michalak, R., and Grassi, G.: First signs of carbon sink saturation in European forest biomass, Nature Clim. Change, 3, 792-796, doi:10.1038/nclimate1853,2013.

Peylin, P., Law, R. M., Gurney, K. R., Chevallier, F., Jacobson, A. R., Maki, T., Niwa, Y., Patra, P. K., Peters, W., Rayner, P. J., Rödenbeck, C., van der Laan-Luijkx, I. T., and Zhang, X.: Global atmospheric carbon budget: results from an ensemble of atmospheric $\mathrm{CO}_{2}$ inversions, Biogeosciences, 10 , 6699-6720, doi:10.5194/bg-10-6699-2013, 2013.

Piao, S., Ciais, P., Friedlingstein, P., Peylin, P., Reichstein, M., Luyssaert, S., Margolis, H., Fang, J., Barr, A., Chen, A., Grelle, A., Hollinger, D. Y., Laurila, T., Lindroth, A., Richardson, A. D., and Vesala, T.: Net carbon dioxide losses of northern ecosystems in response to autumn warming, Nature, 451, 49-52, doi:10.1038/nature06444, 2008.

Raupach, M. R., Canadell, J. G., and Le Quéré, C.: Anthropogenic and biophysical contributions to increasing atmospheric $\mathrm{CO}_{2}$ growth rate and airborne fraction, Biogeosciences, 5, 1601-1613, doi:10.5194/bg-5-1601-2008, 2008.
Rayner, P. J., Law, R. M., Allison, C. E., Francey, R. J., and PickettHeaps, C.: The interannual variability of the global carbon cycle (1992-2005) inferred by inversion of atmospheric $\mathrm{CO}_{2}$ and $\delta^{13} \mathrm{CO}_{2}$ measurements, Global Biogeochem. Cy., 22, GB3008, doi:10.1029/2007GB003068, 2008.

Revelle, R. and Suess, H. E.: Carbon dioxide exchange between atmosphere and ocean and the question of an increase of atmospheric $\mathrm{CO}_{2}$ during the past decades, Tellus, 9, 18-27, 1957.

Saleska, S. R., Miller, S. D., Matross, D. M., Goulden, M. L., Wofsy, S. C., da Rocha, H. R., de Camargo, P. B., Crill, P., Daube, B. C., de Freitas, H. C., Hutyra, L., Keller, M., Kirchhoff, V., Menton, M., Munger, J. W., Pyle, E. H., Rice, A. H., and Silva, H.: Carbon in Amazon forests: unexpected seasonal fluxes and disturbance-induced losses, Science, 302, 1554-1557, 2003.

Sarmiento, J. L., Hughes, T. M. C., Stouffer, R. J., and Manabe, S.: Simulated response of the ocean carbon cycle to anthropogenic climate warming, Nature, 393, 245-249, 1998.

Sarmiento, J. L., Gloor, M., Gruber, N., Beaulieu, C., Jacobson, A. R., Mikaloff Fletcher, S. E., Pacala, S., and Rodgers, K. Trends and regional distributions of land and ocean carbon sinks, Biogeosciences, 7, 2351-2367, doi:10.5194/bg-7-23512010, 2010.

Schuster, U. and Watson, A. J.: A variable and decreasing sink for atmospheric $\mathrm{CO}_{2}$ in the North Atlantic, J. Geophys. Res., 112, C11006, doi:10.1029/2006JC003941, 2007.

Sitch, S., Smith, B., Prentice, I. C., Arneth, A., Bondeau, A., Cramer, W., Kaplan, J. O., Levis, S., Lucht, W., Sykes, M. T., Thonicke, K., and Venevsky, S.: Evaluation of ecosystem dynamics, plant geography and terrestrial carbon cycling in the LPJ dynamic global vegetation model, Glob. Change Biol., 9, 161-185, doi:10.1046/j.1365-2486.2003.00569.x, 2003.

Smith, B., Prentice, I. C., and Sykes, M. T.: Representation of vegetation dynamics in the modelling of terrestrial ecosystems: comparing two contrasting approaches within European climate space, Global Ecol. Biogeogr., 10, 621-637, doi:10.1046/j.1466822X.2001.t01-1-00256.x, 2001.

Tarantola, A.: Inverse Problem Theory and Methods for Model Parameter Estimation, SIAM, (ISBN 0-89871-572-5), 342 pp., 2004.

Wang, X., Piao, S., Ciais, P., Friedlingstein, P., Myneni, R. B., Cox, P., Heimann, M., Miller, J., Peng, S., Wang, T., Yang, H., and Chen, A.: A two-fold increase of carbon cycle sensitivity to tropical temperature variations, Nature, 506, 212-215, 2014.

Xu, L., Myneni, R., Chapin, F., Callaghan, T., Pinzon, J., Tucker, C., Zhu, Z., Bi, J., Ciais, P., Tommervik, H., Euskirchen, E., Forbes, B., Piao, S., Anderson, B., Ganguly, S., Nemani, R., Goetz, S., Beck, P., Bunn, A., Cao, C., and Stroeve, J.: Temperature and vegetation seasonality diminishment over northern lands, Nat. Clim. Change, 3, 581-586, doi:10.1038/nclimate1836, 2013.

Zhou, L. M., Tucker, C. J., Kaufmann, R. K., Stayback, D., Shabanov, N. V., and Myneni, R. B.: Variations in northern vegetation activity inferred from satellite data of vegetation index during 1981 to 1999, J. Geophys. Res.-Atmos., 106, 20069-20083, 2001. 